\title{
Investigating Factors Affecting Entrepreneurship Development in Botswana
}

\author{
Ishmael Radikoko \\ University of Botswana \\ Baagi Maswabi \\ University of Botswana \\ Mashoko Dzimiri \\ University of Botswana
}

\begin{abstract}
This study was conducted in order to explore the factors that affect entrepreneurship development in Botswana. Furthermore, it went on to investigate if there is any relationship between education and entrepreneurial success. Lastly the paper investigates problems and some of the barriers that hinder potential entrepreneurs from engaging in new venture creation or enhancement of existing businesses. The data used for this research was collected through the use of questionnaire which was distributed to respondents in the two most populated cities of Botswana being Gaborone and Francistown. The results shows that the main factors that affect entrepreneurial development in Botswana are, Research and Development; Education \& Training; Government Entrepreneurial programs and Government Policies which are all found to constrain entrepreneurship development because they are lacking in terms of advancing entrepreneurial activity in Botswana. The results further show that there is no strong relationship between education and entrepreneurship development. Lastly the results of this study show that bureaucracy and ineffective implementation of government policies stifles entrepreneurial development. We recommend that the government should review its policies meant to enhance entrepreneurial activity because to date they have been found to be ineffective. Further, the education system especially targeted at entrepreneurial development has to be revamped to align it to the ones observed in successful nations across the globe. Lastly bureaucracies in govern structures that are meant to enhances entrepreneurial development has to be minimized.
\end{abstract}

Keywords: Botswana, Entrepreneurship, Entrepreneurship Development, Entrepreneurial Education

\section{INTRODUCTION}

Entrepreneurship is a process of creating a new economic entity centered on a novel product or service or at the very least one which differs significantly from products or services offered elsewhere in the market, Henry, Hill, and Leitch (2005). On the other hand Global Entrepreneurship Monitor (GEM) defines entrepreneurship as "any attempt at new business or new venture creation, such as self-employment, a new business organization, or the expansion of an existing business, by an individual, a team of individuals, or an established business (GEM Global Report, 2012). Entrepreneurship is the engine of economic growth and development and well natured entrepreneurship activities contribute positively to the economy of a nation 
and also improve the quality of life of the people [Morris \& Lewis (1991), Adejumo (2001)]. Van Praag and Versloot (2008) adds to this by showing that entrepreneurship contribute to employment creation, productivity growth and innovation. However, (Sternberg and Wennekers, 2005) though in agreement with other scholar, are of the view that different economies are impacted differently and by different stages of entrepreneurship in different parts of the world in term of improved economic performance.

Youth entrepreneurship in particular, has a greater potential to aid in the achievement of reduced unemployment rates. The issues of economic growth, innovation of companies and the creation of jobs are problems that in the last decade have affected society and in general, different governments and public administrations. Entrepreneurship activity is one of the solutions to some of these various problems. In Botswana the government is striving to diversify the economy; several initiatives have been put in place to accomplish this objective. One of such initiatives is encouragement of citizens to establish businesses through funding from Citizen Entrepreneurship Development Agency, Youth Development Fund, Youth Empowerment Scheme, The Young Farmer's Fund and obtaining advisory and mentorship services through The Local Enterprise Authority.

Botswana is on the road to recovery from the 2008 Global financial recession; as such the country needs to tackle challenges ranging from unemployment (especially among the youth) to issues like poverty eradication. Entrepreneurship is the way forward; therefore this phenomenon ought to be studied in detail so as to understand it and how it can be improved. This study is conducted for this very purpose.

\section{STATEMENT OF THE PROBLEM}

Entrepreneurship development forms the bedrock of all business evolutions and economic miracles of the nation. The most common problem of entrepreneurship development is a lack of funding and difficulty in securing a loan from financial institutions (Deolankar, 2014). In the case of Botswana; the government has attempted to bridge this gap by establishing venture capital schemes such as Youth Development Fund, Youth Empowerment Scheme and Young Famers' Fund and the establishment of Citizen Entrepreneurial Development Agency. This presents Batswana with a unique opportunity to startup businesses. This study shall investigate further to find out the factors that affect entrepreneurship development. Most of the promotional activities of the government have been directed around financial and physical facilities with the illusion that there will be an automatic flow of entrepreneurs if such facilities are created. Research by (Deolankar, 2014) has proven that financial and physical facilities are not the only crucial external environment inputs in entrepreneurship development. This study shall further find out the other crucial external environment inputs needed for entrepreneurship development.

\section{RESEACH OBJECTIVES}

The main objective of this study is to find out the factors that affect entrepreneurship development. Other objectives include the following:

- To find out whether entrepreneurial education is vital for business success

- To find out problems and some of the barriers that hinder potential entrepreneurs from engaging in new venture creation or enhancement of existing businesses.

\section{LITERATURE REVIEW}

\section{Factors that affect entrepreneurship development}

The Global Entrepreneurship Monitor (GEM), the largest ongoing study of entrepreneurial dynamics in the world has identified nine factors that influence entrepreneurial development 
and this include entrepreneurial finance, Government policy, Government entrepreneurial Programs, Entrepreneurial education, Research and development transfer, Commercial and legal infrastructure, Entry Regulations, Physical Infrastructure and culture and social norms. In light of these factors, GEM Botswana 2012 report, which is the first national report on entrepreneurship activity by GEM in Botswana, shows that all these factors identified fails to stimulate entrepreneurship in Botswana, save to physical Infrastructure factor which appear to be the only factor positively contributing to entrepreneurship development in Botswana although just marginally. The report further shows that the lowest contributors to entrepreneurial development are Research and development transfer, Education and Training, Government entrepreneurship programs and Government policies. The report reveals that $\mathrm{R} \& \mathrm{D}$ transfer is considered the most constraining factor to entrepreneurship development in Botswana. It show that, the of use latest technology emanating from $R \& D$ remains an issue to new and growing firms which stifles their ability to compete and survive. Entrepreneurial education and training has also found to be lacking in Botswana despite the fact that the importance of education cannot be overemphasised. DeJaeghere and Baxter (2014) demonstrate that entrepreneurship education has been found to be the solution to problem of unemployment and poverty in Sub-Saharan Africa.

Other research has discovered that entrepreneurship is influenced by other factors which include economic development, culture, technological development and education. In areas where these factors are present, one can expect to see strong and consistent entrepreneurial growth. (Relivingmbadays, 2012). Economic factors that affect entrepreneurship development include capital, labor, raw materials, market and infrastructure. (Relivingmbadays, 2012). Social factors that affect entrepreneurship development include caste factor, family background, education, attitude of the society and cultural value. Psychological factors affecting entrepreneurship development include need achievement, withdrawal of status respect and motives. (Relivingmbadays, 2012)

A study conducted in Kenya has exposed that the majority of the youth have poor credit access individually mainly from financial institutions as well as Youth Enterprise Fund. (Rambo, 2014) Access to entrepreneurship education and Business development services during the start-up and growth phase also affected many young entrepreneurs. The socio economic factor such as unemployment led many youth to participate in business. (Rambo, 2014)

In the case of India, most of the promotional activities are directed around the financial and physical facilities with a strong belief that there will be automatic flow of entrepreneurs if such facilities are created in backward states of India. (Deolankar, 2014) The author of the paper, Vivel Deolankar says in spite of abundant natural resources, the pace of industrial and entrepreneurial development is slow not only because of lack of basic facilities and financial institutions, but due to untapped entrepreneurial talent in the country and suggests that timely action by the government and other agencies should be taken to improve entrepreneurship development in India. (Deolankar, 2014)

\section{Entrepreneurial education and success}

DeJaeghere and Baxter (2014) demonstrate that entrepreneurship education has been found to be the solution to problem of unemployment and poverty in Sub-Saharan Africa. These positive impact of entrepreneurship education has actually nullified the believe that somebody should be born an entrepreneurship to become successful in business (Kuratko, 2005). Despite the importance of entrepreneurship education and training as revealed by empirical research the rate of education and training remains low in Sub-Saharan Africa (GEM 2012 Sub-Saharan 
report). In Botswana alone, GEM 2012 report shows that education and training is the second lowest contributor to entrepreneurship development

A study conducted by a team of researchers (Kamruzzaman, Zafour, \& Asaduzzaman, 2014) revealed that entrepreneurship development is not impulsive; it depends on various factors like economic, social, political, psychological factors. The study pointed out that the importance of entrepreneurial education and training for motivating educated youth to self-employment is recognized by development economists, planners and policy makers; as well as government of most countries of the world.

\section{Problems associated with entrepreneurship development}

The 2012 GEM Botswana report reveals that entrepreneurial development in Botswana is constrained by lack of abilities and knowledge to start up a business and also ineffective implementation of intellectual property rights. The latter implies that entrepreneurial ideas are not protected and that lead to unathorised use and undue benefiting through intellectual property such as music, arts and information technology which end up demotivating the inventors and leads to crippling of entrepreneurial innovation and development. Other issues identified in Botswana related to poor access to finance businesses and even if it is avaibled through government polies like introduction of CEDA, Young farmers fund, youth development fund and the like then it becomes very difficult to access the funding because of bureaucracies and stringent loan requirements (GEM Botswana 2012, Mgaya and Magembe, 2007).

In other countries like India at present, the small entrepreneurs are facing various problems like wrong location, improper estimation of capital cost, delayed and cost escalation, inadequacy of finance, delayed payment, deficiency in the management, non-availability of raw materials, poor maintenance of plant and machinery, low labor productivity, hardship in marketing outlets. Labor troubles have been as much responsible for lack of growth in entrepreneurship as inflation, demand recession and the well-known "get rich quick" techniques. Another major problem is the lack of training facilities in management, technical and other skills, which is necessary for the development of entrepreneurship in India. (Deolankar, 2014)

\section{Barriers that hinder potential entrepreneurs from engaging in new venture creation}

Unstable political conditions where government policies change frequently discourage new business formation, as investors fear for the safety of their investment. Governments support economic development through infrastructure development, facilitation, industrial parks. These activities encourage entrepreneurship and if a government does not engage in such it creates a barrier for new venture creation. (Nayab \& Edwards, 2011) The availability of infrastructure and utilities such as roads, power, communication facilities and lack of corruption and bureaucratic delays in obtaining such utilities encourage entrepreneurship. (Jambheshwar, 2014) The general purchasing power of the people, manifested by income levels and economic prosperity of the region, plays a major role in the success of entrepreneurial ventures. (Caser, Mogollon, \& Roldan, 2014)

\section{Influence of Culture on Entrepreneurship}

What makes some entrepreneurs tick while others fail? Why do people in some cultures and regions display a better entrepreneurial spirit compared to people in other cultures. In their study (Nayab \& Edwards, 2011) find out how cultural factors influence entrepreneurship. Culture affects entrepreneurship in many ways, for instance; people engaged in jobs and other services pressure their children to find secure jobs and crush their entrepreneurship spirit at a very early age. However, people traditionally engaged in businesses have a pro-business 
attitude and disdain working as employees. Business school students come under missionary zeal of teachers who exhort them to become entrepreneurs even if the opportunity cost is very high. The study also reveals how political environment supports or suppresses entrepreneurship. Unstable political conditions where government policies change frequently discourage business, as investors fear for the safety of their investment. Government support to economic development through infrastructure development, facilitation, industrial parks, and the like all encourage entrepreneurship. The availability of infrastructure and utilities such as roads, power, communication facilities, and lack of corruption and bureaucratic delays in obtaining such utilities encourage entrepreneurship. The general purchasing power of the people, manifested by income levels and economic prosperity of the region, plays a major role in the success of entrepreneurial ventures. (Nayab \& Edwards, 2011)

Based on the above literature the following main hypotheses can be formulated for this study: H1: The main factors that affect entrepreneurial development in Botswana are

- Research and Development (R\&D)

- Education \& Training

- Government Entrepreneurial programs

- Government Policies

H2: There is strong appositive relationship between Education and entrepreneurial successes

H3: Bureaucracy and ineffective implementation of government policies stifles entrepreneurial development

\section{Study Design}

\section{METHODOLOGY}

The research strategy that is used in this study is survey. (Saunders, Lewis, \& Thornhill, 2009) hold the view that a survey strategy, which is usually associated with the deductive approach, is effective in answering who, what, where, how much and how many questions. It is popular as it allows the collection of a large amount of data from a sizeable population in a highly economic way. This is important as resources for research are usually limited and this one will be no exception. Survey strategy is also perceived as authoritative by people in general and is both comparatively easy to explain and understand. This study is undertaken using the survey strategy on young entrepreneurs in Botswana as well as potential young entrepreneurs. The self-administered questionnaires were distributed in various in the two main cities of Gaborone and Francistown as the 2011 population census reveals that these are the areas with high concentration of youths.

\section{Data, population and sampling scheme}

The study uses both primary and secondary data. Primary data will be obtained by the use of self-administered questionnaires. Secondary data is collected by reviewing the existing literature and identifying themes and issues related to the perceptions on factors that affect entrepreneurial opportunity recognition. Newspapers, journals, books and articles will be used to collect relevant information.

The population in this research is all young Batswana within the age range of 0yrs to 35yrs. We decided to focus on the youth particularly because they are an interesting group in that they form almost $70 \%$ of the population according to the 2011 Botswana population census statistics. The sample of the study is 1000 young Batswana entrepreneurs consisting of 500 females and 500 males. This study is focused on getting insights (perceptions) of young entrepreneurs on issues affecting entrepreneurial development. The study is carried out in Gaborone and Francistown guided by population statistics as mentioned earlier. A total of one 
thousand (1000) questionnaires were distributed in Gaborone and Francistown. The study adopts non probability sampling techniques or purposive sampling which allow the researchers to use own judgment to select cases that will answer the research questions (Saunders et.al, 2009). Out of the 1000 questionnaires distributed only 800 were returned which represent $80 \%$ response rate.

\section{FINDINGS \& DISCUSSIONS}

The data collected through the questionnaires distributed is processed using the Statistical Package for Social Sciences (SPSS) software version 22. This enables a comprehensive data analysis with the use of cross tabulations, mean comparisons, percentages and frequencies. Qualitative data shall be subjected to appropriate analysis. This paper focused on the factors that affect entrepreneurship development as well as establish if education is a key ingredient for the success of businesses in Botswana. We also present under this section the results of other issues which addresses the objectives as stated at the beginning of this research.

\section{Factors That Affect Entrepreneurship in Botswana}

First we start with presentation of results which addresses the factors that affect entrepreneurship in Botswana. One of the question that we asked respondents was "what do you think are the factors that affect entrepreneurial development in Botswana?"

The responses to these questions were mixed (See table 1 below) but majority of the respondents (80\%) mentioned the following factors as affecting entrepreneurship development. Lack of training/education; Lack of start-up Capital; Small population (lack of market); Lack of support from established businesses; Lack of Financial discipline; Lack of innovative business ideas

Lack of entrepreneurial training and education in general, as well as lack of financing was mostly (90\% of respondents) mentioned by respondents as affecting development of entrepreneurship in Botswana. Other factors had between $50 \%$ and $70 \%$ of respondent mentioning them as affecting entrepreneurship development. With these findings we therefore fail to reject the hypothesis (H1) that, the main factors that affect entrepreneurial development in Botswana are R\&D transfer, Education \& Training, Government Entrepreneurial programs, Government Policies. From these hypotheses, lack of R\&D transfer is supported by the fact that respondents mentioned lack of innovative ideas as one of the factor. Innovation is linked to R\&D because without research there will be no innovative business ideas. Moreover, the other problem that has been identified by respondents being lack of market cannot be addressed because it is through innovation that new products and services can be produced and hence penetrating new markets or the same market but offering differentiated service or products. $\mathrm{R} \& \mathrm{D}$ also can lead to new or improved technologies; however the study has shown that local entrepreneurs do make an effort to utilize the latest technology. Social media such as Facebook, twitter, Instagram, email, WhatsApp and many more are utilized by entrepreneurs to advertise as well as communicate with clients, so lack of use of these technologies to promote businesses in Botswana might also be associated with the problem of lack of market as mentioned by respondents. Themba and Josiah (2015) suggest that another problem of dealing with demand side of products and serviced to increase profitability is to improve the marketing skills of promoters so that they can lure customers to their businesses and deal with this problem of lack of market. 
Table 1: Summary of Reponses for Factors as Affecting Entrepreneurship Development in Botswana

\begin{tabular}{|l|l|}
\hline Lack of startup Capital & Market saturation \\
\hline Low Population size & Stiff competition \\
\hline Lack of skilled labor & Small market \\
\hline High rental cost & Lack of Business Land \\
\hline Lack of creativity/innovation & Monopoly by big companies \\
\hline Lack of support from family, friends and government & Culture \\
\hline Lack of political influence & Job security \\
\hline
\end{tabular}

With regards to lack of finance, the study found out that despite that the government has come up with venture capital schemes; entrepreneurs are still having problems in terms of obtaining funding. This could be attributed to the stringent requirements of the venture capital schemes. Figure 1 below is an illustration of sources of capital for new venture creation. According to the figure, most entrepreneurs fund their businesses using personal savings. The bar graph shows that government funding is the least utilized source of capital with less than $5 \%$ of the respondent showing that they managed to access government funding for their businesses. This shows that there could be some policy issues with regards to government funding schemes available. These results suggest that there are bureaucracies in government with regards to accessing services and resources that can enhance entrepreneurship. This is despite the abundance of such programs and policies which government has put in place to support entrepreneurial development. We can therefore conclude that the implementation of such programs is not effective and something has to be done to improve the efficiencies in terms of implementation and reduced burecracies. This finding suggest that we fail to reject (H3) stated in this research that bureaucracy and ineffective implementation of government policies stifles entrepreneurial development in Botswana. The findings are consistent with those of [Mgaya and Magembe, (2007), Gagoitseope and Pansiri, (2012), and GEM Botswana 2012 report] who all anonymously agree that despite the abundance of government programs and policies geared at enhancing entrepreneurial development in Botswana, entrepreneurial activity remains low. The other issue observed is that in some government funding schemes it appears that government funding is only for specified line of business and ignore some business when it comes to funding projects. According to the list adopted from the Youth Development Fund application guidelines there are a number of businesses that would not be funded altogether through the scheme and these include: Bar/Bottle Store/Liquor Restaurant/any other alcohol related projects; Cash loans; Night clubs; Phone shops; Livestock speculation; Public Transport; Any other illegal business

The non-funding of these projects impact those who want to venture into these businesses. The reason behind non-funding of these could be because the areas are already saturate in the market and hence limited profitability. Other reasons could also be that the businesses are illegal and some of these businesses are against other government policies, e.g the government is currently striving to reduce alcohol consumption in the country as can be evidenced by the introduction of alcohol levy. As such it would be contradictory for the government to support through funding such business ideas to do with production or distribution of alcohol which include Bars, liquor restaurants and night clubs as examples. Despite funding issue raised by respondent as one of the factors affecting creation of new ventures, Themba \& Josiah (2015), rule out financing as a sufficient condition for formation of new ventures, they suggest that a more comprehensive environment has to be facilitated and they argue that there is need to improve the marketing skills of promoters so that they can deal effectively with demand related challenges so as to improve profitability of their business and hence their success. 
Figure 1: Different Sources of Capital

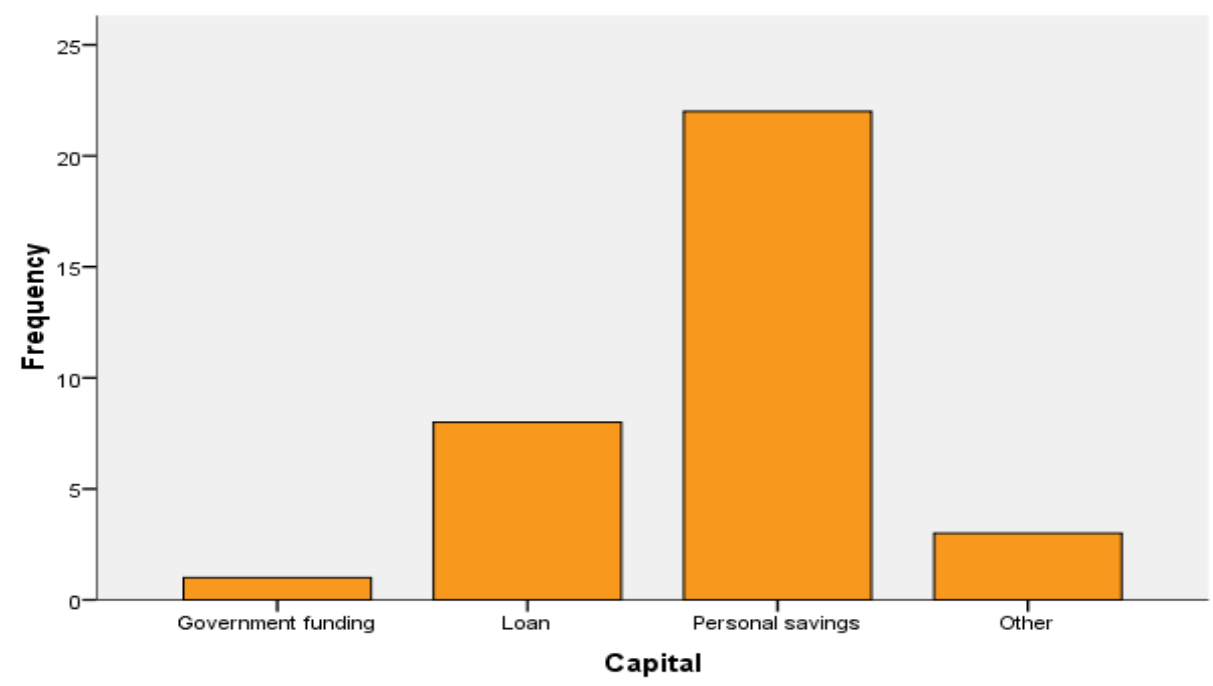

\section{Education and the Success/Failure of Businesses}

One of the key objectives of this research is to find out whether entrepreneurial education is vital for business success. In this section we do analysis to establish whether the respondents have a certain level of education because education has be found to contribute significantly to successful businesses [Charney and Libecap (2000), DeJaeghere and Baxter (2014)].

We therefore model the relationship between education and business success using information gathered from our respondents to check if indeed there is any positive relationship between the two as literature suggest.

We use number of years in business as an indicator of success of failure and also checked the correlation between education and numbers of years in business. The assumption is that the longer a business stays in operation it is deemed to be successful; since if it is not successful it would shut down at-least in a year or at most in three years. We modeled our data such that the dependent variable is the number of years the business has been operating. The independent variable is the level of education the entrepreneur has attained. Different levels of education (Ranging from JC to professional courses were converted into years such that JC=10years, BGCSE=12yrs, CERTIFICATE=14yrs, DIPLOMA=15yrs, DEGREE=16yrs, MASTERS=18yrs, PHD=22yrs, PROFESSIONAL=16yrs, for ease of quantitative analysis. JC stands for Junior Secondary Education; BGCSE refers to Botswana General Certificate of Secondary Education. The rest are conventional qualification generally known in the education system. The number of years for all the different level of education are assigned based on average number of years expected to be taken for different level of education as per Botswana's education system. The whole idea here is to ascertain whether level of education attained can effectively determine whether a business will be successful. The results of our analysis are presented below and we start with the general descriptive statistics.

Table 2: Descriptive Statistics

\begin{tabular}{|l|c|c|}
\hline & Mean & N \\
\hline Number Of Years In Business & 6.31 & 320 \\
\hline Level Of Education & 14.88 & 320 \\
\hline
\end{tabular}


$\mathrm{N}$ in table 2 is the value of the total number of entrepreneurs who answered the question about the number of years they have been operating their business. The other questionnaires had missing values either because the respondent was an aspiring entrepreneur or just unwilling to divulge the information. The mean for number of years in business is 6.31years showing that most businesses are around 6years old. The mean for level of education is 14.88years, this number is approximately 15years; therefore, on average the respondents have attained at least a Diploma.

Next we present the results of correlation using Pearson correlation statistics.

Table 3: Correlation Analysis

\begin{tabular}{|l|l|c|c|}
\hline & & $\begin{array}{l}\text { Number of } \\
\text { years } \\
\text { business }\end{array}$ & $\begin{array}{l}\text { Level } \\
\text { education }\end{array}$ \\
\hline \multirow{2}{*}{ Pearson Correlation } & Number of years in business & 1 & 0.244 \\
\hline \multirow{2}{*}{ Sig. (1-tailed) } & Level of education & 0.244 & 1 \\
\hline \multirow{2}{*}{$\mathbf{N}$} & Number of years in business & $\cdot$ & 0.089 \\
\cline { 2 - 4 } & Level of education & 0.089 &. \\
\hline & Number of years in business & 320 & 320 \\
\cline { 2 - 4 } & Level of education & 320 & 320 \\
\hline
\end{tabular}

In the above table $3, \mathrm{~N}$ represents the number of respondents to the questionnaire who actually answered the two questions about number of years in business and level of education. According to Pearson Correlation the correlation between number of years in business and level of education is 0.244. This correlation is classified by Cohen (1988) as small (Pallant, 2010). These results suggest that we reject (H2) that there is a strong positive relationship between education and entrepreneurial success. The results run contrary to our expectation since a larger correlation would have been logical given what literature suggest. The information below presents further analysis of the results to unpack further as to why our results ran contrary to the expectation.

Table 4: R-Square Analysis

\begin{tabular}{|c|l|c|c|}
\hline Model & R & R Square & Std. Error of the Estimate \\
\hline 1 & .244 & 0.06 & 6.366 \\
\hline
\end{tabular}

a) Predictors: (Constant), LEVEL OF EDUCATION

b) Dependent Variable: NUMBER OF YEARS IN BUSINESS

The R-square value of $(0.06)$ means that only $6 \%$ of the variability in the number of years in business can be accounted for by level of education. This questions whether level of education is a good predictor of business success or in this case number of years spent doing business. The standard error of the estimate is 6.366, it is the amount of error associated with regression analysis in terms of predicting a particular value. (Pallant, 2010)

The Anova table quantifies whether the correlation value of 0.244 is statistically significant. The $\mathrm{F}$ value is 1.9 and the statistical significance is at 0.178 . The level of statistical significance does not indicate how strongly the two variables are associated, but instead it indicates how much confidence we should have in the results obtained. (Pallant, 2010) A statistical significance of 0.178 means we can be confident that the results are statistically significant 
meaning that indeed attainments of education do not necessarily transform someone to be a successful entrepreneur.

Table 5: Analysis Of Variance (Anovab)

\begin{tabular}{|l|l|l|l|l|l|l|}
\hline \multicolumn{2}{|l|}{ Model } & $\begin{array}{l}\text { Sum of } \\
\text { Squares }\end{array}$ & Df & $\begin{array}{l}\text { Mean } \\
\text { Square }\end{array}$ & F & $\begin{array}{l}\text { Si } \\
\text { g. }\end{array}$ \\
\hline \multirow{4}{*}{1} & Regression & 77.02 & 1 & 77.02 & 1.9 & $\begin{array}{l}.1 \\
7 \\
8^{\mathrm{a}}\end{array}$ \\
\hline & Residual & 1215.855 & 30 & 40.529 & & \\
\hline & Total & 1292.875 & 31 & & & \\
\hline
\end{tabular}

a) Predictors: (Constant), LEVEL OF EDUCATION

b) Dependent Variable: NUMBER OF YEARS IN BUSINESS

In summary the results generally shows that there is no strong relationship between education and entrepreneurial success. The findings tend to support the believe that somebody should be born an entrepreneurship to become successful in business (Kuratko, 2005). These results are surprising as they run contrary to abundant literature which is in favor to the fact that education is a key to entrepreneurship success. As an example Charney and libecap (2000) shows that graduate who have been exposed to entrepreneurial education tend to be more successful in both starting up business as well as at their place of work if they decide to take a job instead of stating up a business upon graduation. They discovered this after comparing the career paths of graduates that had completed the entrepreneurship program at the University of Arizona to business school graduates of the same institution who were never exposed to entrepreneurial concepts. Bailey (2007) share the same sentiments and show that education, training, work experience, apprenticeships, overseas visits and other human capital development initiatives are relevant for entrepreneurial success or failure to the extent that they contribute to the development of entrepreneurial competences. DeJaeghere and Baxter (2014) add to this and demonstrate that entrepreneurship education has been found to be the solution to problem of unemployment and poverty in Sub-Saharan Africa

\section{SUMMARY OF RESULTS}

Overall results of this study in relation to stated objectives and hypotheses are summarized in the table below.

Table 6: Summary of Results

\begin{tabular}{|c|c|c|}
\hline Objective & Hypothesis & Reject/Fail to reject \\
\hline $\begin{array}{l}\text { 1. To find out Factors that } \\
\text { affect entrepreneurial } \\
\text { development in Botswana }\end{array}$ & 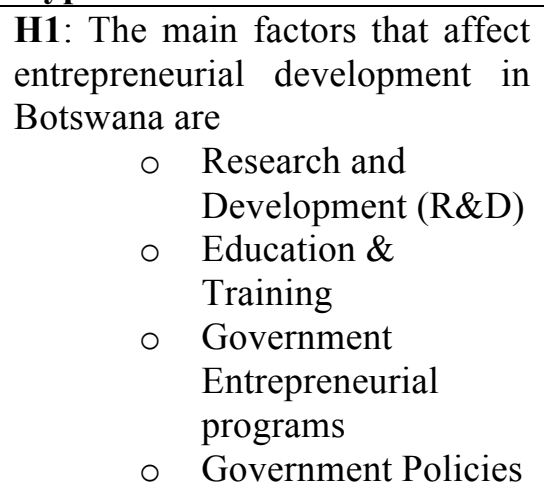 & H1: Fails to be rejected \\
\hline $\begin{array}{l}\text { 2. To find out whether there is } \\
\text { relationship between } 1 \\
\text { education and business } \\
\text { success }\end{array}$ & $\begin{array}{l}\text { H2: There is strong appositive } \\
\text { relationship between Education } \\
\text { and entrepreneurial successes }\end{array}$ & H2: Rejected \\
\hline
\end{tabular}


3. To find out problems and some of the barriers that hinder potential entrepreneurs from engaging in new venture creation or enhancement of existing businesses.
H3: Bureaucracy and ineffective implementation of government policies stifles entrepreneurial development
H3: Fails to be rejected

\section{CONCLUSION}

This study was conducted in order to explore the factors that affect entrepreneurship development. Entrepreneurship is indeed crucial to the health of any nation's economy. The paper was an attempt to better understand this phenomenon in the context of Botswana, especially among the youth since they are the most affected by adverse economic conditions; specifically unemployment. The paper also went on to investigate if there is any relationship between education and entrepreneurial success. Lastly the paper also went further to investigate problems and some of the barriers that hinder potential entrepreneurs from engaging in new venture creation or enhancement of existing businesses. The data used for this research was collected through the use of questionnaire which was distributed to 1000 individuals in the two most populated cities of Botswana being Gaborone and Francistown.

The results of the study shows that the main factors that affect entrepreneurial development in Botswana are : Research and Development (R\&D); Education \& Training; Government Entrepreneurial programs and Government Policies which all of them are found to be crippling entrepreneurial development in Botswana because they are all lacking in terms of advancing entrepreneurial activity. The results further show that there is no strong relationship between education and entrepreneurship development. This runs contrary to the research done by (Deolankar, 2014) entitled entrepreneurship in India. In his paper he states "One of the major external environment inputs that drastically affects entrepreneurship development is entrepreneur education." Furthermore the results contradict the result of [Charney and libecap (2000); Bailey (2007); Deolankar, 2014 and DeJaeghere and Baxter (2014)] who all suggest that education is the key ingredient to any successful business venture.

Lastly the results of this study shows that bureaucracy and ineffective implementation of government policies stifles entrepreneurial development and this is an area which will need further research to establish what could be real problem, that is, are the policies themselves not comprehensive and address real issues or whether ineffective implementation of these policies is the real problem. Moreover, further research need to be carried out find our why there are bureaucracies that makes huddles for successful entrepreneurial activity and suggestions made to remove these red tapes. Lastly, research has to be carried out to establish why education does not seem to positively impact the development and success of entrepreneurship. It has to be established as to whether the education offered is just general and not entrepreneurial.

\section{RECOMMENDATIONS}

This paper examined the factors that affect entrepreneurship development in Botswana. These four factors that have been found to constrain entrepreneurial development are R\&D transfer, Education and Training, Government entrepreneurial programs and Government policies. We recommend that the government should review its policies meant to enhance entrepreneurial activity because to date they have been found to be ineffective. If the review suggests that the policies have been drafted properly then the next step is to insure effective implementation of 
those policies to make sure they achieve their objectives and also to minimize bureaucracies that have been found to be prevalent in Botswana. Other findings in this study show that Batswana culture is not conducive for local entrepreneurs; there is a perception that foreign goods are superior to local goods is very biased and a major drawback to Batswana entrepreneurs. The respondents to the questionnaire highlighted that there is a law of "buy Botswana" which lacks implementation. Policies that promote local entrepreneurs ought to be encouraged through promotion and consumer education. The average Motswana has proven not to give much thought to where they are taking their business; Batswana have an apparent negative attitude towards locally produced products. Firstly local entrepreneurs have to rise up to the challenge to produce competitive products and services of high quality; then this notion of undermining local goods and services would be crushed. Furthermore, Batswana need to be educated on the importance of supporting local entrepreneurs; this would greatly help local businessmen who are being choked by their foreign counterparts.

Further on the issue of education, the education system especially targeted at entrepreneurial development has to be revamped to align it to the ones observed in successful nations across the globe where entrepreneurship is successful as a result of it. We recommend that the whole syllabus for entrepreneurship education be revised so that it can include the very crucial practical aspect of entrepreneurship. This can be done through institutions that offer entrepreneurship education forming partnerships with established entrepreneurs such that aspiring-student entrepreneurs can get practical insight into what entrepreneurship is really like. Entrepreneurs may be invited to conduct some of the lectures and students can visit their areas of business operation to see how things are done. Innovation and creative thing has to be encouraged by government and the private sector and funding should be availed to carry out research and development that has potential to bring new discoveries and innovative ideas.

Furthermore, Botswana has a major issue of youth unemployment; the blunder is encouraging youth that do not have experience in business to sojourn into the wilderness of venture creation by themselves. Most government venture capital schemes are targeted at the youth in order to solve unemployment; the challenge is that the youth are not interested in businesses such as farming which require one to be confined to a rural area, an idea which is infamous among the youth. Batswana in the older age brackets who have the experience and willingness to undertake farming (both arable and pastoral) have been side lined in terms of funding. A gap exists between those who have the ability to venture into farming and accessibility to funding, to bridge this gap; apart from prerequisites such as ownership of land, an additional requirement of partnering with older experienced farmers ought to be included in the necessities for funding.

Botswana is a country with a lot of potential; it is a unique example of what Africans can build without much foreign assistance. This genius ought to be portrayed in the arena of entrepreneurship. The country is ripe for investment with one of the best infrastructure and utilities such as roads, communications and is a possible power-house through its massive coal production. The only thing that is required is entrepreneurial ingenious and the country will continue to prosper.

\section{References}

1. Adejumo, G. (2001). Indigenous entrepreneurship development in Nigeria: characteristics, problems and prospects. Advances in Management: Journal of Department of Business Administration, University of Ilorin, Ilorin Nigeria, 2(1): 112-122.

2. Bailey, H. (2007). Entrepreneurial spirit as crucial driver for Development and Cooperation: Wittenberg Centre for global ethics. Discussion paper 
3. Bolton, B., \& Thompson, J. (2001). Entrepreneurs Talent, Temperament, Technique. London: ButterworthHeinemann.

4. Caser, J. C., Mogollon, R. H., \& Roldan, J. L. (2014, 10 21). Environmental Factor that Influence the Entrepreneurial Capacity. An Empirical Approach from the GEM project using a structural equation model. Retrieved from www.gemconsortium.org

5. Charney, A. \& G.D. Libecap (2000). Impact of Entrepreneurship Education. Kansas City, MO: Kauffman Center for Entrepreneurial Leadership

6. DeJaeghere, J. and Baxter, A. (2014). Entrepreneurship education for youth in sub-Saharan Africa: A capabilities approach as an alternative framework to neoliberalism's individualizing risks, Progress in Development Studies, Vol. 14, No.1, pp.61-76.

7. Deolankar, V. (2014, October 13). Entrepreneurship Development in India. Retrieved from Google: www.books.google.co.bw

8. Gagoitseope, P. K, and Pansiri J., (2012), Evaluation of Critical Success Factors for Developing Small and Medium-Sized Enterprises in Botswana, Journal of African Business, Vol. 31. No. 1, pp. 51-61.

9. GEM Botswana 2012 national report. Retrieved from http://www.gemconsortium.org/report

10. Henry, C., Hill, F., \& Leitch, C. (2005). Entrepreneurship education and training: can entrepreneurship be taught? Part I. Education+ Training, 47(2), 98-111.

11. Jambheshwar, G. (2014, 10 21). Entrepreneurship Development and New Enterprise Management. Retrieved from www.ddegjust.ac.in

12. Kamruzzaman, M., Zafour, A., \& Asaduzzaman, K. M. $(2014,10$ 18). Factors Influencing Entrepreneurship Development in Barisal Metropolitan City: Problem and Prospect. Retrieved from Google: www.scrib.com

13. Kuratko, D. (2005). The Emergence of Entrepreneurship Education: Development, Trends, and Challenges. Entrepreneurship, Theory and Practice, Vol 29, No.5, 577-598.

14. Mgaya, K.V. and Magembe, B.A., (2007), Attitudes of University Students Towards Entrepreneurship, World Review of Entrepreneurship, Management and Sustainable Development, Vol. 3, No. 2, pp.192-206.

15. MindQ. (2015, March 16). Welcome to CEDA. Retrieved from CEDA: www.ceda.co.bw

16. Morris, M. H. and Lewis, P. S. (1991). Entrepreneurship as a significant factor in social quality of life. Journal of Business Research, 23(1):21-36.

17. Nayab, N., \& Edwards, G. (2011, 11 19). Factors Having an Impact on Starting and Operating a Business. Retrieved from Bright Hub: www.brighthub.com

18. Pallant, J. (2010). SPSS Survival Manual. New York: Allen and Unwin Book Publishers, Australia.

19. Population and Housing Census, (2011), Statics Botswana, Gaborone, Botswana

20. Rambo, D. C. $(2014,1021)$. Factors Influencing the Development of Youth Entrepreneurship in Ongata Rongai Township, Kajiado County: Kenya. Retrieved from University of Nairobi: Department of Extra Mural Studies: www.ems.uonbi.ac.ke

21. Relivingmbadays. (2012, 12 26). Relivingmbadays. Retrieved from Relivingmbadays: www.relivingmbadays.wordpress.com

22. Saunders, M., Lewis, P., \& Thornhill, A. (2009). Research Methods for Business Students. Essex: Pearson Education Limited.

23. Sternberg, R., \& Wennekers, S. (2005). Determinants and effects of new business creation using global entrepreneurship monitor data. Small Business Economics, 24(3), 193-203.

24. Themba, G. and Josiah, J. (2015). Entrepreneurship Development in Botswana Lessons for Other Developing Countries, Botswana Journal of Business, Vol. 8, No.1, pp. 11-35

25. Van Praag, C.M. and Versloot, P.H. (2008). The Economic Benefits and Costs of Entrepreneurship: A Review of the Research. Foundations and Trends ${ }^{\circledR}$ in Entrepreneurship, 4(2). 